\title{
Una historia de \\ Larga duración: \\ La navidad
}

\section{RESUMEN}

Raquel Barceló Quintal *

Actualmente, para la mayoría de los pueblos del planeta, los doce días relacionados con la fiesta de Navidad representan el nacimiento de Jesús en Belén. Sus antecedentes se remontan a casi 4,000 años, cuando estas fiestas estaban relacionadas con la renovación de la naturaleza. Es hasta 345 años después de la muerte de Cristo, cuando el papa Julio I, fijó como fecha del natalicio de Cristo el 25 de diciembre. No sólo la Iglesia católica participó en la historia de esta festividad, en ella entran los pueblos mediterráneos de Europa, Asia y África; y más tarde las culturas americanas hicieron su parte para incorporar nuevos elementos a esta tradición.

\section{Abstract}

For the majority of Christian communities in the world, the twelve days related to the celebration of Christmas represent the birth of Jesus in Bethlehem. The antecedents of this story reach back almost 4,000 years when the celebrations were related to the rebirth of nature. Pope Julius I fixed the 25th of December as Christ's birth date 345 years after His death. The Catholic Church is not the only participant in the history of the celebration; communities in Mediterranean Europe, Asia and Africa also participated. Later, American cultures have also contributed new elements to the tradition.

\section{De la fiesta pagana a la fiesta cristiana}

La historia de las fiestas decembrinas inicia en el Mediterráneo, dos mil años antes del nacimiento de Jesús en Belén con el ritual de la renovación o llegada del año nuevo. Los hombres nacidos milenios antes del nacimiento de Cristo y los que han vivido en los dos últimos milenios después de su muerte, han construido la Navidad como un telar, donde muchos tejedores combinan en él los motivos de la experiencia de su vida, cuando aparece una generación, la siguiente prosigue la obra donde la había dejado la anterior. Así el dibujo del tejido va cambiando conforme se va transformando la mente, pero nunca empieza de nuevo.

Mesopotamia es la cultura más antigua en celebrar los "doce días" o festejos de Año Nuevo, que eran considerados por los mesopotámicos como un momento de crisis para dar paso al orden, con el inicio del año. La historia inicia cuando Babilonia se convirtió en la capital de Mesopotamia, Marduk - el dios supremo de los babilonios, persas y asirios- era quien regía la vegetación y el poder fecundante de las aguas. El Enûma Elish cuenta la historia del nacimiento de Marduk, sus gestas heroicas y cómo llegó a convertirse en el señor de los dioses, cuando

* Doctora en Historia, profesora investigadora del Área de Historia y Antropología, Instituto de Ciencias

y Humanidades, Universidad Autónoma del Estado de Hidalgo. Correo electrónico: raquel_barcelo@yahoo.es 
los Annunki se reunieron para encontrar un dios que pudiese derrotar a Tiamat, la Serpiente del Caos, quién contestó a ese llamado fue Marduk. En la lucha entre Marduk y Tiamat, ganó el primero y le arrebató a su contrincante las Tabletas del Destino, que poseía ilícitamente.

Bajo el reinado de Marduk se creó a la raza humana para que llevasen las cargas de la vida, de manera que los dioses pudiesen disfrutar del ocio. Sin embargo, a Marduk le correspondía proteger la vida. En otoño cuando las cosechas ya se habían recogido, el vacío de los campos indicaba que la vida se moría, era el momento en que Marduk tenía que combatir al monstruo del caos y alejarlo para que la muerte no sea completa. El rey debía morir al final del año para acompañar al dios al mundo inferior y combatir a su lado mientras en la tierra tomaba su lugar un nuevo rey. Luego surgió la idea de un sustituto, real o supuesto, papel que desempeñaba un criminal, a quién vestían con ropas regias y le rendían homenaje "a cuerpo de rey". Terminados los festejos le daban muerte en lugar del verdadero rey (Count, 2000:22).

Los persas y babilonios continuaron con la costumbre pero introdujeron algunas variantes al rito: el sacrificio de un chivo en el altar de sus dioses y la presencia de otro, el "chivo expiatorio". La finalidad del primer sacrificio era limpiar los pecados cometidos por el pueblo, durante todo el año, y la comparecencia del "chivo expiatorio" era para transmitirle, a través de su cabeza, los pecados del pueblo y ofrecerlo al demonio, a este último no lo sacrificaban, lo soltaban en el desierto.

La práctica de los rituales de fin de año se desplazó hacia Occidente y se difundió en Grecia donde las festividades de renovación era la lucha entre Zeus y Cronos. Hesíodo quién nació en Beocia, pero procedía del noroeste del Asia Menor, refleja esas culturas cuando narra las fiestas de renovación; es decir, encontramos en ellas elementos de origen ario, anatólico y egeo fundidos. Las fiestas de renovación en Grecia eran conocidas como sacaea y de ahí se extendieron a Fenicia, Chipre y Roma. En este último lugar, el equivalente a Cronos era Saturno y las festividades se transformaron en las saturnalias, que se celebraban cuando el solsticio llegaba y anunciaba el invierno, momento que se aprovechaba para las festividades ya que se disponía de un período de cierto relajamiento en las labores del campo.

Las saturnalias iniciaban, a mediados de diciembre, con un sacrificio en el templo de Saturno, seguido de un banquete público. Duraban hasta el primero de enero, en medio quedaba el 25 de diciembre, día que, según los cálculos romanos, el sol estaba en su punto más bajo de su recorrido, justo antes de volver a elevarse para transmitir su fuerza a todo lo que crece en la tierra e inmediatamente venían las calendas de enero. En las festividades, amos y esclavos comían juntos y a veces intercambiaban sus puestos. Se elegía a uno de los esclavos para que fungiera como jefe del festejo de la casa.

Las saturnales romanas y las calendas se caracterizaban por bulliciosas. Las calles eran el espacio de las festividades, los romanos iban disfrazados por ellas, organizaban comilonas, visitaban a los amigos, les deseaban buena fortuna e intercambiaban regalos llamados strenae. Éstos consistían en frutas cuya finalidad era desear suerte durante el año venidero. Esta costumbre se remonta a tiempos de Tacio, rey de los sabinos. 
La tradición pasó de Roma hacia los pueblos eslavos. En el Báltico denominaron a estos días de fiesta: koleda, kolyada, koledos, nombres derivados de calendas. Retomando la línea de Occidente, de Roma pasó a España, como una festividad cristiana. Mientras, en el Danubio y los Balcanes, las saturnalias eran bárbaras ya que los soldados elegían por sorteo a uno de ellos para ser rey saturnino de la celebración, durante treinta días le daban de comer, le permitían todos los caprichos y formaban a su alrededor un grosero y bullicioso cortejo, transcurridos los treinta días, tenía que ponerse en el altar y darse muerte (Count, 2000:28).

Los doce días de las saturnalias estaban llenos de augurios; a cada uno de los días le correspondía un mes, por el mismo orden. Así, observando el sol, el viento, la lluvia y la nieve de cada uno de los días, auguraban cómo iba a ser el tiempo de los meses venideros. Junto a esta costumbre, estaba también la de golpear a las personas con ramas verdes para asustar a los demonios y desearles buena suerte en el próximo año. Las ramas verdes significaban el reino del verano; a la llegada del otoño el verdor de los campos iba cambiando a los tonos naranja y amarillo, a excepción de las plantas perennes, y durante el invierno, los demonios invernales se encargaban de matar la vegetación. A estos demonios les asustaban las ramas verdes porque el verde pertenecía al reino de la vida. El poder de los demonios invernales duraba hasta la Candelaria, el 2 de febrero.

La tradición del árbol inicia en la Antigüedad, desde el segundo y tercer milenio a. C., una variedad de pueblos indoeuropeos que se expandían por Europa y Asia tenían a los árboles como expresión de las fuerzas de la Madre Naturaleza y les rendían culto. Para muchas culturas era esencial un árbol en sus celebraciones de invierno. Culturas como la vikinga en países escandinavos, o la celta en Inglaterra y Francia, ya decoraban los robles con frutas para honrar a sus dioses y a sus cosechas. A los pueblos antiguos tenían que haberles parecido que el sol brotaba periódicamente de la vida, según James G. Fraser brotaba del fuego que residía en el roble sagrado (Fraser, 1956).

El ritual de fin de año viajó por otro ruta distinta a las dos anteriores, pasó por los Balcanes y subió por el Danubio, donde, muy desfigurada y empobrecida entró en el mundo pagano de los pueblos nórdicos. En la medida que el ritual era aceptado por las diferentes culturas, también se iba remodelando. Por otro camino llegó la tradición a Israel, donde finalmente se detuvo junto al pesebre de Belén; pero pasó mucho tiempo en que la religión cristiana descubriera que necesitaba la Navidad. Los cristianos vieron en Cristo el "chivo expiatorio" que lavó los pecados de la humanidad y entonces Cristo se convirtió en parte de la fuerza con que su fe conquistó todo el Mediterráneo pagano.

Roma fue el escenario de una nueva imagen navideña, el nacimiento de Cristo, 345 años después de su muerte, el papa Julio I, por falta de documentos y de la certeza del día de su nacimiento, fijó como fecha del acontecimiento el 25 de diciembre, que caía a la mitad de las saturnalias, después del Adviento y antes de la Epifanía o de la Manifestación del Señor, en donde se englobaba la Adoración de los Reyes Magos y el Bautismo. Algunos historiadores señalan que el nacimiento de Jesucristo fue entre el 17 de diciembre y el 29 de mayo y hacen oscilar los años entre 147 y 148 de la fundación de Roma. 
Una vez instituido el nacimiento de Cristo, en los países cristianos empezaron a celebrar la "Misa de Cristo" (Crist's Mass, convertido en Christmas) que dura doce días. Estas misas se llevaban a cabo para ahuyentar a los demonios: rezar traía además bendición en el hogar y para las personas; el espacio de la Navidad empezó a trasladarse a las iglesias.

Paralelamente, a finales del siglo III y en el IV, durante los reinados de los emperadores romanos Dioclesiano, Maximiliano y Constantino, vivió en Bari una provincia de Asia Menor, San Nicolás. Hijo de padres cristianos y acomodados, siendo joven fue consagrado obispo de Mira, una ciudad con puerto al mar. A la muerte de sus padres heredó de ellos: una fortuna sustancial y una consciencia cristiana, extraña para su época, la dádiva. Aprendió de las escrituras: "Cuando des limosna, que tu mano izquierda no sepa lo que hace la derecha, para que tu limosna sea hecha en secreto". Su fortuna la repartió entre los necesitados y un hecho de su vida lo inmortalizó: Cuando pasó ante la casa de un noble, viudo y venido a menos, no pudo evitar escuchar como padre e hija se lamentaban de su anterior fortuna. Aquel hombre tenía tres hijas casaderas pero no tenía con qué alimentarlas ni vestirlas, y mucho menos para darles una dote. A Nicolás todavía le quedaban tres bolsas de oro de su herencia, aquella noche regresó a la casa del noble con una de las bolsas y la tiró por una ventanita. Ysucedió que la hija mayor encontró marido. Pronto le llegó su turno a la segunda hija, y Nicolás repitió el acto. Cuando le tocó el turno a la más pequeña, volvió con su tercera bolsa de oro, pero al tirarla por la ventana, el padre corrió tras él, lo agarró de las ropas y se echó de rodillas y le exclamó: "Nicolás ¿por qué escondernos tus buenas obras?" Pero éste le exigió que no se lo contase a nadie.

Siendo Nicolás obispo, un noble envío a Mira a sus hijos jóvenes, para que los bendijera. Se detuvieron para pasar la noche en una posada, y mientras dormían, el posadero los mató para robarles sus pertenencias. El obispo tuvo una visión y se presentó en busca del posadero y lo encaró con sus crímenes, quién aterrado cayó a sus pies para implorar perdón. Nicolás oró y Dios devolvió la vida a los chicos. Después de su muerte, el 6 de diciembre del año 326, fue canonizado convirtiéndose en San Nicolás. Fue el patrono de los marinos, de los comerciantes - porque en aquel entonces, el comercio estaba relacionado con el mar-, de los piratas, de los viajeros, de la gente humilde, de niños y jóvenes, y de las muchachas solteras. Después de canonizado, fue recordado cada 6 de diciembre, fecha de su fallecimiento, en varios países vinculándolo a las fiestas invernales.

\section{Aportes a la Navidad en la Edad Media}

La Edad Media, que comenzó en el año 476 con la caída del Imperio Romano de Occidente por los bárbaros y que finalizó en 1453 con la caída del Imperio Romano de Oriente, continuaron las prácticas paganas. En la Temprana Edad Media, Roma declinó, pero la Iglesia cristiana sobrevivió. Los misioneros cristianos se dieron a la tarea de introducir a los bárbaros del norte al cristianismo.

Antes que llegaran los misioneros, los bárbaros sabían que al otoño le seguía el invierno, que con su llegada las hojas cambiaban de color. Relacionaban el verdor de las hojas con la vida, por lo tanto interpretaban que empezaban a morir, excepto los árboles y arbustos perennes por lo que eran considerados sagrados. Las saturnalias sufrieron cambios entre los pueblos 
bárbaros del norte, pero conservaron los cantos, regalos, predicción del futuro y la comida y bebida en exceso en esos días (Davis, 1992). Los nórdicos no elegían a un rey fingido sino a un "Señor del desahogo", un "Abad de la Sinrazón", un "Rey de las habas" o un "Papa" que eran vestidos de payasos de nariz roja y que montados en burros iban corriendo a las iglesias o la catedral donde celebraban una misa bufa; mientras que, el coro iba cantando con andrajos o con mantos vueltos al revés (Bayless, 1996). Pese a que fue difícil dominar las saturnales, poco a poco se iban moderando sus efectos.

Cuando llegaron los misioneros, al norte de Europa, descubrieron que las culturas celebraban el nacimiento de uno de sus dioses (probablemente Frey), adornando un árbol perenne. Este árbol simbolizaba al universo, llamado Divino Yggdrasil, en cuya copa se hallaba el cielo, Asgard (la morada de los dioses) y el Vahalla (el palacio de Odin); y en las raíces más profundas del árbol estaban los infiernos. Más tarde, los daneses y noruegos, se expandieron sobre el imperio carolingio; es decir, sobre Inglaterra, Escocia e Irlanda; y sus vecinos, los suecos, se dirigieron a Rusia (Pirenne, 1978:23). Con las expansiones se transmitieron varias costumbres, entre ellas la de adornar los árboles.

Bonifacio (680-750), arzobispo de Maguncia, apóstol de Alemania, y evangelizador de Baviera, Turingia, Sajonia y Frisia, escribió una carta, en el año 742, donde se quejaba con el papa Zacarías de sus esfuerzos retardados por convertir a los paganos francos y alemanes, debido a las prácticas por las festividades paganas. Cuando trató de apartarlos de los abusos, le respondieron que dichas prácticas se celebraba en Roma, a la sombra de San Pedro.

Bonifacio erradicó el árbol pagano entre los alemanes; se dice que tomó un hacha y cortó el árbol que representaba al universo y en su lugar plantó un pino, que simbolizó el amor a Dios, adornándolo con manzanas y velas; las manzanas representaban el pecado original y las tentaciones, mientras que las velas hacían alusión a Jesucristo como la luz del mundo. En la mitad del siglo VIII, surgió otra leyenda cristiana, en la que un roble que los paganos creían sagrado, cayó sobre un abeto, pero éste quedó milagrosamente intacto y por su forma triangular se explicó que representaba a la Santísima Trinidad, con el Dios Padre en la cúspide. Para los bretones, el origen del árbol de Navidad se debe a Persifal, caballero de la mesa redonda del rey Arturo, mientras buscaba el Santo Grial o cáliz de la última cena de Jesús. Persifal vio un árbol lleno de luces brillantes, que se movían como estrellas.

En la Alta Edad Media, es decir en los siglos IX y XI, existía una relación estrecha entre el hombre y la naturaleza. Es decir, ésta última, en sus diversas manifestaciones, formaba parte de la cotidianeidad del hombre medieval. Sin embargo, la relación no era idílica, el hombre se encontraba estrechamente dependiente de la naturaleza y, lo que sin duda era mucho más grave, se hallaba prácticamente inerme ante sus desbordamientos (Slacher Van Balth, 1974).

Cuando llegaba el final del otoño, los campesinos recogían la cosecha y encerraban al ganado, antes de que cayeran las nevadas. Los largos meses del invierno los hacía previsibles, preferían matar parte del ganado a correr el riego de reducir su número, ya sea por las fuertes nevadas o porque morían de hambre en caso de no alcanzara el heno almacenado. La carne del ganado sacrificado la salaban o ahumaban para conservarla, utilizando una parte para las festividades 
que la guisaban para invitar a los amigos a comer. Antes de la cena daban gracias a sus dioses, Thor, Odin, Njord, Frey, a quienes les ofrecían algo de carne, cerveza o hidromiel, con la finalidad de que les concediese un mejor año venidero. Miniatura de Diciembre, Cardenal Doménico Grimani,

Breviario Grimani, 1477

En Inglaterra, Frey era el dios que cuidaba los rebaños y hacía que fueran abundantes, de su nombre procede el nombre inglés del viernes, Friday. Su animal simbólico era el cerdo, por eso cuando llegaba el otoño se sacrificaba un cerdo, cuya cabeza era presentada con una manzana en la boca y se le trataba como si fuese un regio personaje: tocaban las trompetas antes de colocar la cabeza humeante sobre la mesa, vítores, risas y brindis, eran necesarios antes de la cena.

En el siglo $X$, las escuelas de la Edad Media estaban relacionadas con los monasterios. Allí, los maestros animaban a los niños a que presentasen obras de teatro y espectáculos sobre la vida del santo que más admiraban. Los chicos se tomaban muy en serio sus papeles. El rey Conrado I de Alemania habla de una visita a un monasterio en el momento en que los chicos estaban representando al arzobispo Nicolás y su cortejo eclesiástico, que llenaban solemnemente la nave de la iglesia. Las procesiones, con las que los chicos festejaban el día de su santo patrón, salían de los monasterios y pasaban por las calles de la ciudad. El 6 de diciembre, elegían un "niño obispo" y formaban su comitiva. Iban en tropel por las calles recogiendo el tributo de los ciudadanos, cuando llegaban a la catedral, el pequeño obispo entraba en el coro y el presbiterio, participaba en la misa e incluso daba un sermón. La fiesta de los niños duraba hasta el 28 de diciembre, el día de los Santos Inocentes.

En la Baja Edad Media (siglos XI al XV), el tiempo tenía dos referentes fundamentales: 1) uno de carácter físico, el sol y 2) otro de tipo cultural, las campanas de las iglesias. Las veinticuatro horas, se dividían, de acuerdo con las horas canónicas. Cada tres horas las campanas de las iglesias anunciaban el rezo correspondiente: a medianoche, Maitines; a las tres, Laudes; a las seis, Prima; a las nueve de la mañana, Tercia; al mediodía, Sexta; a las 15 horas, Nona; a las 18, Vísperas; y a las 21, Completas.

Si el día se dividía en horas canónicas, ¿Qué era el calendario anual, sino la relación de las fiestas de la Iglesia? Así, por ejemplo, el 11 de noviembre era, ante todo, el día de San Martín; el 6 de diciembre, el día de San Nicolás; el 25 de diciembre, la Navidad; el 6 de enero, el día de los Reyes Magos; el 2 de febrero, el día de la Candelaria, etc. Los domingos, por su parte, se designaban por las primeras palabras del introito de la misa. Llegado el invierno, se situaba la Navidad y la Pascua. En fin, las festividades religiosas servían para contar los años, a partir del nacimiento de Cristo, que se suponía ocurrió el 25 de diciembre del año 753 de Roma (Valdeón Baruque, 2004:48).

A través de testimonios, como poemas y canciones latinas, no religiosos del siglo XIII, como los Carmina Burana, llamado también Codex Buranus, podemos darnos idea de cómo era la sociedad de la época. Unos de los versos que se cantaban cuando finalizaba el año e iniciaba el nuevo era el "Cedit, hiems, tua durities" (Se aleja, invierno, tu dureza) y Anni novi rediit novitas (La renovación del año nuevo vuelve) podemos observar éstos cantos son resabios de las saturnalias. 
En el análisis del conjunto de los cánticos lúdicos-tabernarios podemos tener una idea de la moral de la época, como en la estrofa siguiente:

En este mundo

reina la idolatría;

por doquier se corrompen

el espíritu y sus dones.

Los guardianes son ladrones

y lobos los pastores;

príncipes y reyes

han corrompido las leyes.

(Anónimo, 2006:63)

En el siglo XII, en los países nórdicos la historia del dios supremo Woden, cuyo día era el miércoles, y de ahí el nombre inglés de este día Woden's Day (Wednesday), sufre transformaciones, se le añaden hechos de sacrificio por la humanidad como los de Cristo. En los pueblos escandinavos el nombre de Woden cambió a Odin, quién era representado como con un manto azul, 0 con un sombrero de ala ancha y provisto de su largo bastón de viajero. Odin, quién además era el dios de los guerreros, montaba un corcel blanco (Haskins, 1927). Posteriormente, Odin pasó a ser un dios apacible y cuando se ofreció en sacrificio, para proteger a los escandinavos de los demonios, durante nueve noches, se colgó de un árbol, atravesado por una lanza, era el inicio del invierno. Por eso en las tormentas de invierno lo veían cabalgar en su corcel blanco, pasó a ser el Schimmelreiter (jinete del caballo blanco), vestido con su sombrero y su manto que ondea al viento. Odin aportó a la imagen de San Nicolás, de finales del XVIII y principios del XIX, su sombrero de ala ancha y su fiel caballo blanco.

Los eslavos adoptaron la costumbre cristiana de la Navidad adaptándola a sus costumbres, cenaban en una mesa cubierta con un mantel blanco, debajo de la cual extendían heno y paja para simbolizar el lecho del pesebre y no empezaban a cenar antes de que el cabeza de familia hubiera roto una oblea consagrada y compartiéndola con cada uno de los presentes, como muestra de que estaba dispuesto a compartir con ellos el último bocado, mientras quemaban un madero en la chimenea que purificaba y revitalizaba el fuego que destruía al diablo y al año viejo.

En el siglo XIII, San Francisco de Asís (1182-1226) aportó a la Navidad la costumbre de los nacimientos, al crear por primera vez un nacimiento viviente, en Creccio, población situada entre Roma y Asís, la noche de Navidad de 1225. En una gruta ubicada en la pendiente del monte Lacerne, preparó un pesebre, donde colocó una mula y un buey, unos campesinos representaron a María y José y un pequeño hacía las veces de Jesús, esa noche la cueva se convirtió en una nueva Belén. Ya avanzado el siglo XIII, a los nacimientos vivientes se le acostumbra cantar villancicos, música dulce y delicada, cuya finalidad era elevar los pensamientos a un niño que esperaba una muerte trágica (Sabatier, 1926).

Los países nórdicos, en el siglo XV, conservaron la tradición romana de las ramas verdes para desear buena suerte. En Inglaterra, en el mismo siglo, se sabe de esta costumbre en la Navidad por la obra de John Stown, The Survey of London: 
Durante la Navidad, todas las casas, así como las

iglesias parroquiales, se engalanan con acebo,

hiedra, laurel y cualquier planta verde que se

encontrase en aquella época del año. En la calle, las

fuentes y los postes estaban adornados del mismo

modo.

Las ramas verdes de árboles y arbustos perennes eran colocadas para alejar los males: las agujas de las hojas de acebo eran setos que atrapaban brujas, el enebro alejaba la mala fortuna, las ramas del boj protegía de las enfermedades; en fin, las hojas de la hiedra, laurel, alerce, pícea eran también escudos de protección en el invierno. En Alemania durante los doce días de Navidad colocaban en la casa una escoba con una rama de retama, con la que pensaban que se expulsaba a las brujas y los demonios. En el Tirol, las hojas de enebro eran quemadas para que el humo alejara la mala fortuna, a cada animal le echaban humo y se le rociaba con agua bendita y lo mismo que en los rincones, grietas de la casa, camas y habitaciones; mientras que el granjero iba diciendo: "Bienvenida la buena fortuna, afuera la mala. Finalmente reunía a toda la familia y convidados, los formaba en círculo y cada uno recibía una bendición de humo" (Count, 2000:70). Se creía que para estas fechas los demonios se escondían en los rincones y grietas de las casas, cuya presencia hacía enfermar a niños y ancianos. Por eso en esta temporada las casas lucían coronas verdes en las puertas y ventanas.

Los relatos de la fiesta de la Navidad durante el medioevo no mencionan el árbol navideño, parece ser que Bonifacio y la Iglesia desaprobaron su práctica por su origen bárbaro. Además de las plantas perennes existían otros recursos de defensa como las luces de velas, campanadas, ruidos - como gritos o sonidos de un cuerno o disparos de armas-, por eso, en casi toda la Europa de la Edad Media, el último día era muy sonoro.

\section{Las festividades invernales en la Edad Moderna (Siglos XVI-XVIII)}

Con el siglo XVI inicia una brecha con el mundo medieval, abierta ésta por los descubrimientos geográficos, la ruptura espiritual y física del universo cristiano y la santificación del dinero, que en conjunto van esbozando una nueva percepción del tiempo y el espacio. Las manifestaciones culturales en la Europa, en este siglo, se caracterizaban por su policromía y expresividad, encuadradas en fuertes contrastes, entre las sociedades que viven en las ciudades y el campo, ambas aún sometidas a un ritual rígido y a la vigilancia de la ortodoxia cristiana (Burke, 1974). Las festividades populares eran objeto de particular celo por parte de las autoridades laicas y eclesiásticas. Las festividades religiosas, en cambio, se hallaban sometidas a una liturgia atávica que venía tratando de pulir la Iglesia desde la Antigüedad pagana. En esa época lo que se conservó de las festividades medievales fueron los doce días en que iba muriendo el año viejo y la llegada del año nuevo, momento en que los destinos quedaban suspendidos en la balanza, se decorría un poco el velo del futuro. 
El siglo XVI fue, también, una transición constante en todos los órdenes. El hombre moderno contemplaba el desmoronamiento del feudalismo y la pujanza del capital mercantil, la evolución de las monarquías medievales hacia el autoritarismo, la disociación de la ciencia y el pensamiento del geocentrismo dogmático. Estos procesos revolucionarios no impedían que se mantuviera la vitalidad del mundo rural y se impusiera el ritmo de la civilización campesina. La cultura agropastoril, aunque empezaba a recibir elementos foráneos de la cultura escrita de la ciudad, desde grabados hasta almanaques, todavía formaba parte de la comunidad cultural encabezada por las élites cortesanas (García Martín, 1995:2).

En el siglo XVI a pesar de la presencia moralistas de los protestantes y la celebración del Concilio de Trento por la Iglesia católica, los mandatos religiosos iban por un camino y las tradiciones populares por otro divergente. Las manifestaciones culturales se caracterizaban por su policromía y expresividad, encuadrada en una sociedad de fuertes contrastes, y sometidas a un ritual rígido y a la vigilancia de la ortodoxia cristiana. Las festividades populares eran objeto de particular celo por parte de las autoridades laicas y eclesiásticas, porque tanto en sus manifestaciones lúdicas - danzas, juegos, comedias-como en las religiosas - procesiones, autos, funerales - se hallaban sometidas a una liturgia atávica que venía tratando de pulir la Iglesia desde la Antigüedad pagana (Burke, 1974).

La aculturación cristiana encontraba resistencias en las arcanas mentalidades campesinas. En éstas los ciclos festivos seguían el calendario agrícola de las estaciones del año, en el que las faenas agropastoriles estaban encuadradas por la cronología oficial y dominante de la Iglesia, desglosada en el santoral y en las celebraciones litúrgicas (Huizinga, 1973). Así el otoño, de la naturaleza y de la religión, culminaba con la Natividad y la Epifanía. Con el ocio, forzado por las lluvias y las nieves, las familias campesinas contemplaban la venida del Año Nuevo enfrascadas en labores domésticas de mantenimiento y reparación, tanto de la casa como del espíritu. Las obligaciones de un buen cristiano nos la refiere un flamenco del siglo XVI:

La Navidad la ha tener el hombre con su Señor,

las Carnestolendas con su mujer y la Pascua de

Flores con su cura. (García Martín, 1995.25).

En este mismo siglo, la Navidad sufrió cambios en la Gran Bretaña, los villancicos y el nacimiento en las Iglesias tuvieron un abrupto final en 1552, cuando los puritanos prohibieron la Navidad, aunque regresó su celebración en 1660 con Carlos II.

En las colonias españolas: Nueva España, Guatemala, Cuba y Perú, principalmente, los villancicos y el nacimiento viviente se mezclaron con algunas costumbres prehispánicas. En Nueva España la primera celebración de la Navidad fue en 1528, cuando fray Pedro de Gante reunió a españoles e indígenas, para entonar el himno religioso Hoy nació el redentor del mundo. A partir de entonces, el 24 de diciembre en los atrios de las iglesias se hacían representaciones vivas, procesiones, se rezaba el rosario y al día siguiente desde muy temprano se realizaban oficios en las iglesias (Ajofrín, 1964). En el siglo XVII algunas costumbres chinas llegaron en la nao desde Filipinas a la Nueva España, como los fuegos artificiales y los farolitos chinos, que alumbraban con pequeñas velas. 
En 1621 se concedió permiso a los vecinos de la ciudad de México para adornar e iluminar las imágenes pintadas y de bulto de la virgen María, se le rezaba y se convivía al final con pan, atole y chocolate. En las catedrales de las ciudades se cantaban villancicos en los Maitines (Cruz, 1990).

Hay noticias del uso del árbol navideño a mediados del siglo XVI. Algunos alsacianos habían pasado de las ramas suspendidas al árbol de pie. Una ordenanza forestal de Ammerschweier, en Alsacia, fechada en 1561, decía que ningún ciudadano "tendrá por Navidad más de un arbusto de más de ocho zapatos de longitud" (Count, 2000.80). En un libro de viajes fechado en 1605 se menciona: "por Navidad, en Estrasburgo, ponen abetos en las habitaciones, y cuelgan de ellos rosas cortadas de papel de muchos colores, manzanas, barquillos, adornos dorados, peladillas, etc.".

En Alemania, Inglaterra, Holanda, Suiza, Escandinavia y Rusia solían construir un armazón en forma piramidal para sostener ramas verdes de boj, abeto o pino, que adornaban con papeles de colores y velas. Para los alemanes fue Martín Lutero, el reformador protestante, quien primero colocó velas encendidas a un árbol, y lo hizo para reproducir a su familia la bella escena que vio al caminar una noche de invierno, sorprendido por el brillo de las estrellas que destellaban entre los árboles cercanos. En el siglo XVII, los colonos alemanes llevaron la costumbre del árbol de Navidad a Canadá, al igual que la elaboración de las casitas de jengibre y las galletas navideñas.

El siglo XVII, fue la "época dorada" del pavo en América y Europa, que más tarde sería un elemento importante en la cena de la Navidad. En el invierno de 1621, los colonos ingleses en Plymouth después de lograr su primera buena cosecha celebraron la fiesta de "Acción de Gracias" convocados por William Bradford, gobernador de la colonia. Fue todo un ritual donde el pavo sirvió para agradecer a Dios por la sobrevivencia de los peregrinos en un medio agreste. Desde entonces cada año se empezó a cenar pavo para recordar ese glorioso día.

En Italia, el primer cocinero de la corte de los Gonzaga, en Mantúa, Bartolomeo Stefani, en su libro El arte de la buena cocina (1662) asentó que las lonchas de la pechuga de pavo era una excelente guarnición en los platillos regios, que se popularizo en los banquetes de la mayoría de las casas reales europeas (Barceló, 2002:275). En Francia, los campesinos criaban a los pavos con semillas castañas, almendras y nueces- para engordarlos y darles mejor sabor para ser sacrificados para las fiestas especiales como las bodas y la cena navideña que preparaban en un cocido y rellenado con carnes y vegetales. De esa manera, el pavo daba para comer a toda la familia y ofrecer a las amistades (Barceló, 2002: 276).

En el siglo XVIII, el uso del árbol navideño ya estaba difundido en casi toda Europa. En Alemania el árbol navideño había viajado a lo largo y ancho de su territorio. En 1737, en Wittenberg, una señora de casa solariega, dispuso de tantos abetos como personas a las que iba a hacer regalos. Puso regalos debajo de cada uno, puso velas en ellos y las encendió, y luego llamó a la familia y a los criados. En 1740, estaba tan difundido el árbol que el reverendo protestante Johann Honrad Dannhauer, de Estraburgo, dijo lo que sigue: 
Entre otras bagatelas con lo que se suele distraer la gente durante la Navidad más que en la palabra de Dios, está también el árbol de Navidad, que erigen en la casa, y de él cuelgan muchas muñecas, juguetes y golosinas, y entonces lo agitan y hacen caer esa floración. De donde viene esa costumbre, no lo sé. Es un juego de niños [...]. Mucho mejor sería que los niños se dedicasen al cedro espiritual, Jesucristo (Count, 2000:80)

No se sabe con seguridad cuando se introdujo el árbol en Estados Unidos, probablemente con la migración de alemanes a ese país. Ya en la guerra de independencia se tiene noticia de su presencia, los soldados alemanes de Hesse que el rey Jorge III envió para la guerra, celebraron la Navidad como acostumbraban en su país.

\section{La Navidad en el siglo XIX: de lo público a lo privado}

En el siglo XIX el mundo occidental burgués transformó la Navidad en una ocasión de fiesta familiar. Aunque se conservaron algunos rituales de siglos anteriores, la Navidad, en ese momento, adquirió otro sentido: se disoció de la festividad pública para convertirse en una fiesta familiar. De este modo, la familia se apoderó de las fiestas cristianas para autocelebrarse. A raíz de las dos revoluciones, la industrial y la francesa, se empezó a considerar la estabilidad de la vida familiar como opuesta a la inestabilidad de lo público (Anderson, 1988). Por ello la cena navideña cobró importancia en el ámbito de lo privado, el hogar, y la alegría familiar se convirtió en la razón de ser del espíritu navideño.

Los horarios de las comidas cambiaron en el transcurso del siglo XIX en las ciudades europeas con la presencia del alumbrado de gas en los hogares. En 1825 en Francia se instala el alumbrado de gas en las casas y la cena (souper) se prolongó en la noche; en París, la capital, la cena era una comida fría que se tomaba después de los bailes y las grandes veladas (soirées) a la una o dos de la madrugada. Las cenas y las comidas del domingo se transformaron en un rito familiar, por eso, no es de extrañarse que la cena navideña se convirtiera en el principal rito familiar (Perrot, 1991:226).

Los ritos navideños variaban en la Europa decimonónica, según se estuviera solamente en familia o se hubiera invitado a gentes ajenas al círculo familiar, o de acuerdo a los diversos estratos. También eran diferentes los ritos en las ciudades y el campo (Burnard, 1947). Pero en lo que coincidían estas celebraciones en casi todos los países era el restablecimiento de los lazos familiares que se habían deteriorado en el transcurso del año (Casey, 1987).

La Navidad implicaba una suma de rituales: adornar la casa con el árbol de pino -proveniente de los pueblos escandinavos, que los suevos llevaron durante la Guerra de los Treinta Años a Alemania y que en 1840 pasó a Francia e Inglaterra-, cantar los villancicos - herencia medieval-, la presencia de regalos, los juguetes traídos por Santa Claus —invención estadounidense que proviene de la combinación de San Nicolás y papa Noel-, el envío de tarjetas navideñas aunque la primera se imprimió en 1846, sólo se generalizó en la década de 1870 - la quema del tronco — tradición que viene desde el Medioevo- y la presencia del pavo en la cena, un nuevo elemento que llegó por tres vías: 
1) de los grandes banquetes de la monarquía europea del siglo $X V I I I, 2)$ del consumo del pavo en las fiestas familiares campesinas y 3 ) de la costumbre de comer pavo en el día de Acción de Gracias en Estados Unidos.

En Londres la introducción del pino navideño fue obra del príncipe Alberto, esposo de la reina Victoria y en París su presencia se debió a la princesa Helena de Mecklemburg, duquesa de Orleáns y de las familias protestantes de Alsacia (Perrot, 1991:222). En 1815, la princesa de Nassau-Weilburgo iluminó un árbol en la corte de Viena y animó al Kaiser Francisco I a adoptarlo, ya que se resistía a esta costumbre. De Viena el árbol viajó hasta Praga y de Alemania llegó a Francia. En Estados Unidos en 1851 ya se vendían pinos al por mayor, un granjero de las Catskills, Ilamado Mark Carr, fue el primero en vender árboles de Navidad en Nueva York.

A Estados Unidos se debe el proceso de metamorfosis que llevó al obispo Nicolás de Asia Menor al gordiflón barbudo vestido de rojo y blanco que trae regalos a los niños. Llegó a Norteamérica en el siglo XVII, junto con los colonos holandeses que fundaron Nueva Ámsterdam en la isla de Manhattan, y que más tarde sería Nueva York. Washington Irving, en su Historia de Nueva York (1809) describe a San Nicolás sin ropas de obispo y sin su corcel volador (Irving, 1982). En 1823, en el poema Un relato sobre la visita de San Nicolás, escrito por Clement C. Moore, que apareció en un diario de Nueva York, cambió el caballo volador por un trineo tirado por renos. Lo describe como un tipo alegre, gordo y de pequeña estatura. La imagen como la conocemos actualmente, de mayor estatura, con traje de color rojo y con pieles, se debe al dibujante Thomas Nast, quién publicó sus ilustraciones en la revista Harper's (1860) y le agregó de su fantasía detalles como su taller en el Polo Norte y su vigilancia sobre los niños buenos y malos.

Santa Claus con ropa de obispo, Washington Irving,

Historia de Nueva York 1809

Santa Claus enano, Clemente C. Moore,

"Un relato sobre la visita de San Nicolás", Times, New York, 1823 La quema del tronco adquirió otro significado, en este siglo: el calor familiar durante la cena; mientras que para los campesinos el fuego siguió significando la purificación del nacimiento de Jesús, por lo que la familia permanecía junto al fuego hasta la madrugada esperando la primera misa del día siguiente. Estos últimos conservaron parte de la herencia medieval; es decir, la idea de que mientras se quemaba el tronco en la chimenea, la virgen María entraba a los hogares para calentar al niño Jesús.

El ritual navideño implicaba en las casas católicas instalar nacimientos de arcilla italiana, con siete u ocho personajes, modalidad también de este siglo, ya que antes los nacimientos eran vivientes y propios de la iglesia. Otro elemento antiguo que se desarrolló en el siglo XIX fueron los aguinaldos. Éste se adopta en forma de gratificaciones obligatorias a la servidumbre, al portero, al cartero, como apoyo para su cena navideña. El aguinaldo en los niños se convierte en el regalo de dinero para comprar dulces y juguetes (Perrot, 1991:227). Los niños empezaron a poner en sus zapatos ante la chimenea, con la esperanza de encontrar dinero en ellos para invertirlos en caramelos, soldados y muñecas Grabado “La Navidad”, Biblioteca de Artes decorativas, Paris, 1840. 
A principios del siglo XIX, se introdujo el pavo en la cena en casi todas las ciudades de Europa y fue tan importante como la presencia del pino navideño. En las ciudades, como París, la burguesía suplantó al ganso por el pavo conservando la misma receta: cubriéndolo con una jalea elaborada con trufas y vino blanco. En las principales ciudades de Europa y América las tiendas y carnicerías, en las vísperas de Navidad, lucían colgados en los aparadores pavos ya desplumados listos para rellenar y hornear. Los conventos jesuitas de Francia eran visitados los días cercanos a la Navidad porque vendían los pavos ya rellenados, lo que alivianaban a las amas de casa horas de trabajo en la cocina. La novela de Charles Dickens Cuento de Navidad, escrita en 1843, nos confirma la presencia del pavo para la cena navideña en todas las clases sociales. Los adinerados de Londres servían una variedad de platillos:

Amontonados en el piso, como un trono, había pavos, gansos, pájaros de caza, queso, grandes pedazos de carne, lechones, tiras de salchichas, bizcochos con frutas picadas, pudines de ciruela, barriles de ostras, castaño calientes, manzanas brillantes, naranjas jugosas, peras exquisitas, pasteles enormes y vasos de ponche. Que hacian obscurecer el cuarto por el vapor. Mientras que en las casas humildes de los obreros, sirvientes y burócratas se notaba la escasez: el empleado, Bob Cratchit y su familia [...] cenaban un pequeño pavo y pudín que cocinó su esposa y cantaban villancicos alegremente (Dickens, 1996).

También, como parte de las obligaciones de las familias cristianas, estaba el asistir en la Navidad a la misa de medianoche, y de regreso a su casa cenaban un pavo teniendo como escenario el árbol navideño, simbolizando el amor a Dios. Las velas continuaron como parte importante del árbol representando la luz de Jesucristo y las manzanas, que en las culturas escandinavas y germanas se colocaban para simbolizar el pecado original, fueron suplantadas por esferas, galletas de jengibre y otros adornos. Los profanos, en cambio, asistían al teatro, para luego cenar en casa un pavo y glorificar la felicidad familiar. En Francia se preparaban, además del pavo trufado, la sopa o crema de vainilla con barquillos, la morcilla asada, las frutas escarchadas y mientras el tronco (bûche) se quemaba en la chimenea, lo más ancestral de las tradiciones junto con los villancicos.

La repostería fue importante en la cena, del siglo XIX data el horneo de galletas en su forma actual. Alemania aportó a la Navidad el lebkuchen o pan de jengibre, que data desde la Edad Media, y que fue receta de los pasteleros de Nuremberg y una variedad de galletas: las springerle que son galletas de anís, las butterplatzen, galletas de mantequilla, las zimtsterne galletas en forma de estrella con sabor a canela y que contienen almendras y nueces y las spekulatius (especulador), que recibe San Nicolás para honrarle cuando visita los hogares. Las galletas se difundieron en toda Europa y pronto empezaron las panaderías a lucir en sus aparadores las galletas, empañadillas y biscochos de especias, que contribuyeron en dar a las ciudades el espíritu navideño. En algunas ciudades comenzaron a decorar los pinos con las galletas. El regalar galletas navideñas tiene su origen en la costumbre del siglo XVIII que consistía en repartir panes y bolillos de miel. En ese siglo sólo las personas acaudaladas se podían permitir comprar estos dulces a los vendedores ambulantes o a los panaderos. 
En el México decimonónico el mes de diciembre era el más hermoso y alegre del año, era el mes de las posadas, de las fiestas, de las temporadas de ópera, de las cenas íntimas y de la diversión para todo el mundo. Pobres y ricos procuraban alegrase en la medida de sus posibilidades (López Portillo y Rojas, s/f: 1). En las casas de vecindad se organizaban tandas de Posadas y entre todos los vecinos se repartían las nueve celebraciones; así no salían caras ni gravosas para nadie. Cuando estas fechas se acercaban, los vecinos se ponían de acuerdo y adornaban los patios con farolitos de papel, tiras de colores y heno. A las ocho de la noche llegaba el arpa a una de las viviendas y al poco tiempo todos los vecinos se encontraban ya reunidos con sus mejores galas. Primero se rezaban unas oraciones, después se repartían las velas y empezaba la procesión con la letanía. La vecina, a quien tocaba recibir la posada, obsequiaba a la concurrencia con confites, cacahuates, tejocotes y colación, mientras que los muchachos tocaban pitos de caña (Cuellar, 1947:31).

La Navidad de las clases populares, en México, se celebraba en la vecindad con baile y cena. A las doce en punto se suspendía el baile para presenciar la acostada del Niño en el pesebre y después se pasaba al comedor, donde cenaban: ensalada de Nochebuena, una variedad de platillos de pescado y el un revoltijo con pencas tiernas de nopal desmenuzadas (Cuellar, 1947:165). En la clase media la festividad variaba, las jóvenes tocaban el piano hasta las diez de la noche, pasaban a cenar terminando a la once y media, para asistir a la misa de gallo, donde cantaban en coro y se hacían resonar flautas de hoja de lata, en forma de pequeñas cafeteras llenas de agua, llamadas huijolas (López Portillo y Rojas, s/f: 173). La alta esfera celebraba de otro modo, la casa se iluminaba ricamente, las mujeres adornaban sus escotes con joyas y los hombres, impecables, les hacían juego a ellas dentro de su sobriedad. Después del baile, a las doce se obsequiaba a los asistentes con un exquisito buffet, y se brindaba con champagne (López Portillo y Rojas, s/f:144).

La última noche del año de 1899 a las 12 horas, la ciudad de México despidió el siglo XIX con las campanadas de la catedral, al unísono con las de los demás templos, hasta que el último repiqueteo se ahogó con el clamor de los silbatos de las fábricas, que saludaban al siglo nuevo con chorros de vapor, y el chillido agudo de las locomotora. En el cielo, rasgando el espacio con su luminosa cauda un cohete estalló, desgranándose en multicolor lluvia de estrellas. Un año más llegaba a la vida de los mexicanos y con este comenzaba el siglo XX lleno de esperanzas y promesas (González Peña, 1946:100).

\section{Epílogo}

La Navidad nace en las culturas del Mediterráneo, ya tenía milenios de historia a sus espaldas cuando nació Cristo. Pero es en la Edad media cuando se construyó un nuevo mundo y modeló una nueva persona. La invención de la catedral gótica y los tubos de órgano forman parte de aquella aventura para iniciar con los cánticos de la Navidad; es en esa época también cuando surgen los nacimientos.

Aunque los países Nórdicos aportaron la Navidad tal como la conocemos hoy, su esencia: la fe y la esperanza de un nuevo ciclo venidero ha estado presente durante milenios en diferentes culturas del mundo. Fue el siglo XIX, quien marcó un nuevo estilo de la Navidad con la cena en familia. 
Aunque no se abordó la Navidad del siglo XX, sabemos que ésta es un reflejo de la época: la era del plástico, que acabó con muchos símbolos, al crear árboles y coronas artificiales, aunque ganó en el colorido de las luces. El siglo XX significó para unos, confusión y caos; pero para otros, menos en número, fue mejor que los siglos anteriores, por existir incontables avances científicos y técnicos, y espectaculares progresos. Todo tiene un costo en la vida, el alma de un pueblo que son sus tradiciones han cedido el paso a la comercialización de la Navidad.

Hoy la Navidad sigue significando cena abundante en muchas partes del mundo. Esto se explica porque en las antiguas sociedades donde el hambre era el rey soberano, comer era algo totalmente contrastante, siendo por ello el supremo camino al cielo. Las viandas era el broche de oro para cerrar el año agrícola y cenar en familia era prometer la abundancia relativa para el futuro siempre incierto. Durante el cristianismo Medieval, la cena de Navidad, la presencia de la carne era símbolo de las palabras que Jesús pronunciara en la última cena: "Esta es mi carne". Las carnes que se preparaban para la cena navideña antes del pavo eran de puerco, ganso, pescado, faisán, entre otras, según la región y el estrato social. Aunque el pavo llegó en el siglo XVI a Europa, no es hasta el siglo XIX cuando se convierte en un símbolo importante para la cena, y a pesar de que actualmente, en casi todo el mundo, los tiempos modernos cobra más importancia la gran actividad comercial derivada de la práctica del intercambio de regalos, el pavo sigue siendo símbolo de la Navidad.

En los albores del siglo XXI, nos lleva a pensar en un nuevo orden mundial, en última instancia no será más que el viejo orden mundial, con ropaje diferente, El mundo es mucho más que eso y su complejidad y tradiciones diversas requieren al menos respeto de la globalización.

\section{FUENTES DE CONSULTA}

- AJOFRIN, Francisco (1964), Diario el viaje que, por orden de la sagrada Congregación de Propa

ganda Fide, hizo a la América septentrional en el siglo XVIII. México: Instituto de Cultural His

panomexicano.

- ANDERSON, Michael (1988), Aproximación de la familia occidental. Madrid: Siglo XXI.

- ANÓNIMO, (2006), Carmina Burana. Antología. Selección, traducción y comentarios de

Juan Antonio Estevez Solá. Madrid: Alianza Editorial.

- BARCELÓ, Raquel, (2002), "El guajolote: rey de las mesas", en Cuadernos de Nutrición, Vol.

25, núm. 6, noviembre-diciembre.

- BAYLESS, M., (1996), Parody in the Middle Ages: the Latin Tradition. Ann Arbor, Michigan:

University of Michigan Press.

- BURKE, Peter, (1974). La cultura popular en la Edad Media y el Renacimiento. Barcelona: Barral.

- BURNAND, R., (1947), La vie quotidienne en France (1870-1900), Paris: Hachette. 
- CASEYJ., et al, (1987), Familia y sociedad en el Mediterráneo. Barcelona: Crítica.

- COUNT E. W. y LAWSON COUNT, A., (2000), Historia de la Navidad, Barcelona: José J. de Olañeta, Editor.

- CRUZ, Juana Inés de la, (1990), Villancicos que se cantaron en la catedral de la Puebla de los Ángeles, en los Maitines solemnes del nacimiento de nuestro señor Jesucristo, este año de 1689, Puebla: Gobierno del Estado de Puebla.

- CUÉLLAR, José T. de, (1947), Historia de Chucho el Ninfo. Colección de Escritores

Mexicanos, México: Editorial Porrúa.

- DAVIS, Ch., (1992), “La Edad Media”, en JENKY, R. (Ed.), El legado de la Roma. Una nueva

valoración. Barcelona: Crítica, pp. 62-90.

- DICKENS, Charles, (1996), Canción de Navidad. Barcelona: Lumens.

- FRASER, James G., (1956), La rama dorada: magia y religión, México: Fondo de Cultura

Económica.

- GARCÍA CÁRCEL, Ricardo, (1995), La vida en el siglo de Oro, Madrid: Amoretti.

- GARCÍA MARTíN, Pedro, (1995), Los campesinos del siglo XVI, Madrid: Amoretti.

- GONZÁlEZ PEÑA, Carlos, (1946), La chiquilla. Colección de Escritores Mexicanos,

México: Editorial Porrúa.- HASKINS, Charles Homir, (1927), The Reinaissance of the Twelfth Century. Cambridge, Mas-

sachussets: Harvard University Press.

- HUIZINGA, Johan, (1973), El otoño de la Edad Media: estudios de la forma de vida y del espíritu

durante los siglos XIV y XV en Francia y los Países Bajos, Madrid: Alianza.

- IRVING, Washington, (1982), The legend of Sleepy Hollow, and other selections. Edited and with

an introduction by Austin McCraken Fox, New York: Washington Square.

- LÓPEZ PORTILLO YROJAS, José, (s/f), Fuertes y débiles. México: Librería Española.

- PERROT, Michele, (1991), "La vida de familia", en Philippe Ariès y George Duby (Coords.)

Historia de la vida privada. Vol. 7, La Revolución francesa y el asentamiento de la sociedad bur

guesa, Madrid: Editorial Taurus.

- PIRENNE, Henri, (1978), Historia económica y social de la Edad Media. México: Fondo de Cultura Económica.

- SABATIER, Paul, (1926), L'influence de saint François d'Assise sur la civilisation italienne, Paris:

Ernest Leroux.

- SLACHER Van BALTH, B. H., (1974), Historia agraria de Europa Occidental, 550-1850, Barce-

lona: Editorial Península. 
- VALDEÓN BARUQUE, Julio, (2004), Vida cotidiana en la Edad Media, Madrid: Dastin. 